\title{
Improving outcome of valve replacement for carcinoid heart disease
}

\author{
Anita Nguyen, MBBS, ${ }^{a}$ Hartzell V. Schaff, MD, ${ }^{a}$ Martin D. Abel, MD, ${ }^{\mathrm{b}}$ S. Allen Luis, MBBS, \\ Brian D. Lahr, MS, ${ }^{\mathrm{d}}$ Thorvardur R. Halfdanarson, MD, ${ }^{\mathrm{e}}$ and Heidi M. Connolly, $\mathrm{MD}^{\mathrm{c}}$
}

\section{ABSTRACT}

Objective: Carcinoid heart disease is characterized by tricuspid valve regurgitation and varying degrees of pulmonary valve regurgitation or stenosis. Valve replacement procedures may be complicated by systemic effects of carcinoid syndrome, as well as hepatic dysfunction and right heart failure. This study was performed to identify factors that might be associated with improving early mortality rates and late outcomes.

Methods: Between November 1985 and January 2018, 240 adult patients underwent surgery for carcinoid heart disease at the Mayo Clinic. We analyzed the association of multiple clinical and echocardiographic variables on early mortality and late survival.

Results: The median (interquartile range) age of patients was 63 years (55-69), and 117 patients $(49 \%)$ were male. Before operation, 157 patients $(70 \%)$ had New York Heart Association class III or IV limitation. Somatostatin analogs were used in 221 patients $(92 \%)$, and long-acting somatostatins were used in 130 patients $(54 \%)$. Loop diuretic therapy was used preoperatively in 125 patients $(52 \%)$. Early mortality rate was 29\% (9/22) between 1985 and 1994, but decreased to $7 \%(6 / 81)$ during 1995 to 2004 , and to $5 \%(7 / 128)$ from 2005 onward. Overall survival estimates at 1,3 , and 5 years were $69 \%, 48 \%$, and $34 \%$, respectively. Older age, advanced New York Heart Association class, and a nonlinear effect of creatinine were independently associated with overall mortality.

Conclusions: Valve replacement for carcinoid heart disease has acceptable short-term mortality, and early risk has decreased in the current era. Earlier intervention may improve overall survival. (J Thorac Cardiovasc Surg 2019;158:99-107)

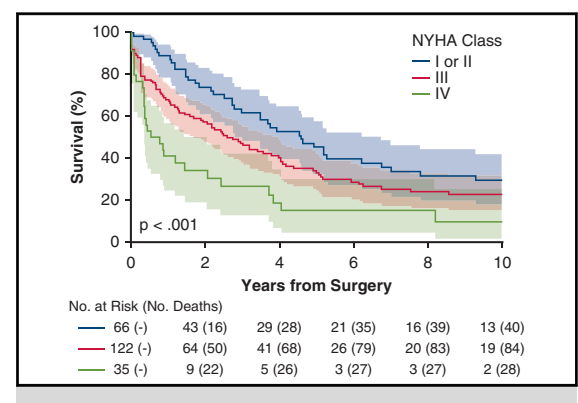

Survival by preoperative NYHA class.

\section{Central Message}

Valve surgery for patients with carcinoid heart disease has acceptable operative mortality. Early operation on patients with lower NYHA class may improve short- and long-term outcomes.

\section{Perspective}

In patients with carcinoid heart disease and symptoms of right-sided heart failure, valve surgery improves functional outcomes. Early operative mortality has decreased significantly over the last decades, but late survival is limited by carcinoid tumor progression. Reintervention due to carcinoid involvement of bioprostheses is rare.

See Commentary on page 108.
Carcinoid tumors are malignancies of the neuroendocrine system. These tumors secrete high levels of vasoactive substances, including serotonin, and typically arise from

\footnotetext{
From the ${ }^{\mathrm{a}}$ Department of Cardiovascular Surgery, ${ }^{\mathrm{c}}$ Department of Cardiovascular Medicine, ${ }^{\mathrm{d}}$ Division of Biomedical Statistics and Informatics, and ${ }^{\mathrm{e}}$ Division of Medical Oncology, Mayo Clinic, Rochester, Minn; and ${ }^{b}$ Department of Anesthesiology, Mayo Clinic, Jacksonville, Fla

This work was supported by the Paul and Ruby Tsai Family.

Institutional Review Board 17-004592 (Approval Date 6/8/2017).

Read at the 44th Annual Meeting of The Western Thoracic Surgical Association, Goleta, California, June 27-30, 2018.

Received for publication June 26, 2018; revisions received Sept 4, 2018; accepted for publication Sept 9, 2018; available ahead of print Dec 6, 2018

Address for reprints: Hartzell V. Schaff, MD, 200 First St SW, Rochester, MN 55905

(E-mail: schaff@mayo.edu).

$0022-5223 / \$ 36.00$

Copyright (c) 2018 by The American Association for Thoracic Surgery

https://doi.org/10.1016/j.jtcvs.2018.09.025
}

the terminal ileum or appendix. Carcinoid syndrome is characterized by facial flushing, bronchoconstriction, and secretory diarrhea and may occur in patients with invasive carcinoid tumors or metastases. Cardiac involvement (carcinoid heart disease) occurs in approximately $20 \%$ to $50 \%$ of patients with carcinoid syndrome. Carcinoid heart disease leads to fibrosis and endocardial thickening of the heart valves and is thought to occur as the result of chronic exposure of valve tissue to high levels of serotonin. ${ }^{1-4}$

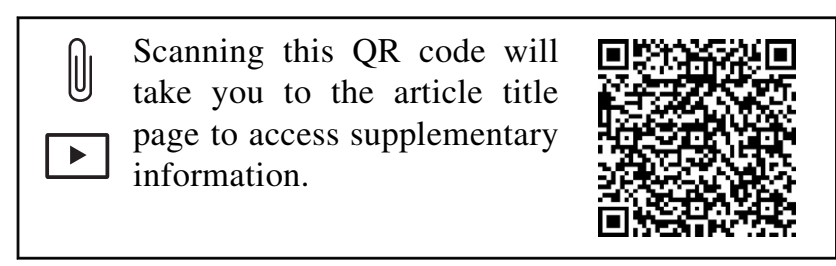




\section{Abbreviations and Acronyms \\ $\mathrm{CI}=$ confidence interval \\ NYHA $=$ New York Heart Association \\ $\mathrm{OR} \quad=$ odds ratio}

assessment included transthoracic echocardiography, and cardiac computed tomography or cardiac magnetic resonance imaging was performed as necessary. All patients underwent assessment of renal and liver function, and coagulation testing before surgery.

Perioperative management of patients with carcinoid heart disease is important to avoid triggering a carcinoid crisis, which is a life-threatening complication that may be exacerbated by general anesthesia and trauma of surgery. A carcinoid crisis is characterized by sudden onset of hypotension (or labile blood pressure), tachycardia, flushing, and bronchoconstriction. To prevent this complication, all patients receive somatostatin analogs preoperatively, which, in current practice, include the long-acting formulation. ${ }^{12,13}$ Patients with very active disease despite outpatient somatostatin therapy are hospitalized preoperatively for intravenous infusion of octreotide (100-200 $\mu \mathrm{g} / \mathrm{h}, 12$ hours preoperatively). The infusion is continued during and after the procedure. If the patient experiences signs and symptoms suggestive of carcinoid crisis, a $1000 \mu \mathrm{g}$ bolus of octreotide is administered with intravenous fluids. ${ }^{4}$

\section{Operative Methods}

Almost all patients with carcinoid heart disease have some degree of tricuspid valve regurgitation, and tricuspid valve replacement is performed in the majority of patients. ${ }^{14}$ In our earlier experience, the pulmonary valve was frequently excised at the time of tricuspid valve replacement. Although pulmonary valve regurgitation was tolerated well early postoperatively, longitudinal follow-up of patients who had pulmonary valvectomy showed increased risk of progressive right ventricular enlargement. ${ }^{15}$ Therefore, it is our practice to replace the pulmonary valve in patients with pulmonary valve regurgitation.

After median sternotomy, we use bicaval cannulation with direct cannulation of the superior vena cava for cardiopulmonary bypass (Video 1). The heart is arrested using cold blood cardioplegia. After snaring the caval cannulas to isolate the right atrium, we make a longitudinal atriotomy and inspect the septum for a defect or patent foramen ovale, which is then closed. Next, the anterior and posterior tricuspid valve leaflets are excised, and the septal leaflet and chordal attachments are left in place. After calibrating the annulus, valve sutures are placed through leaflet tissue remnants in the area of the penetrating bundle of His, and the crossclamp is removed and sinus rhythm restored to allow the heart to beat during the remainder of the procedure.

For pulmonary valve replacement, an incision in the pulmonary artery begins 3 to $4 \mathrm{~cm}$ distal to the valve annulus and is carried across the valve onto the right ventricular outflow tract. Remnants of pulmonary valve cusps are excised, and a large oval autologous pericardial patch is sewn to the pulmonary arteriotomy with 4-0 polypropylene suture. The augmented valve annulus is calibrated, and the appropriate size prosthesis is secured with running 3-0 polypropylene suture that anchors the valve to the native annulus posteriorly and to the pericardial patch anteriorly. The remainder of the pericardial patch is then used to close the ventriculotomy.

\section{Postoperative Management}

The intravenous octreotide infusion is continued in the early postoperative phase until the patient is stable. Anticoagulation with warfarin is instituted in all patients with a target international normalized ratio of 2.5 (range, 2-3) ${ }^{16}$ and is continued for 3 to 6 months for those with biological tissue valves and indefinitely for those receiving mechanical prostheses. Patients should undergo continued surveillance by an experienced cardiology team, with frequent echocardiographic assessment every 3 to 12 months after operation. ${ }^{4}$

\section{Statistical Analysis}

Categorical data are presented as frequencies and percentages, and continuous variables are expressed as medians and interquartile range. Unadjusted survival time was estimated by Kaplan-Meier analysis, with differences determined using log-rank test. In the subset of patients with follow-up of 30 days or more, cumulative incidence of reintervention

\section{Preoperative Assessment and Operative Planning}

All patients included in this study were cared for by a multidisciplinary team with special interest in carcinoid heart disease. Preoperative 

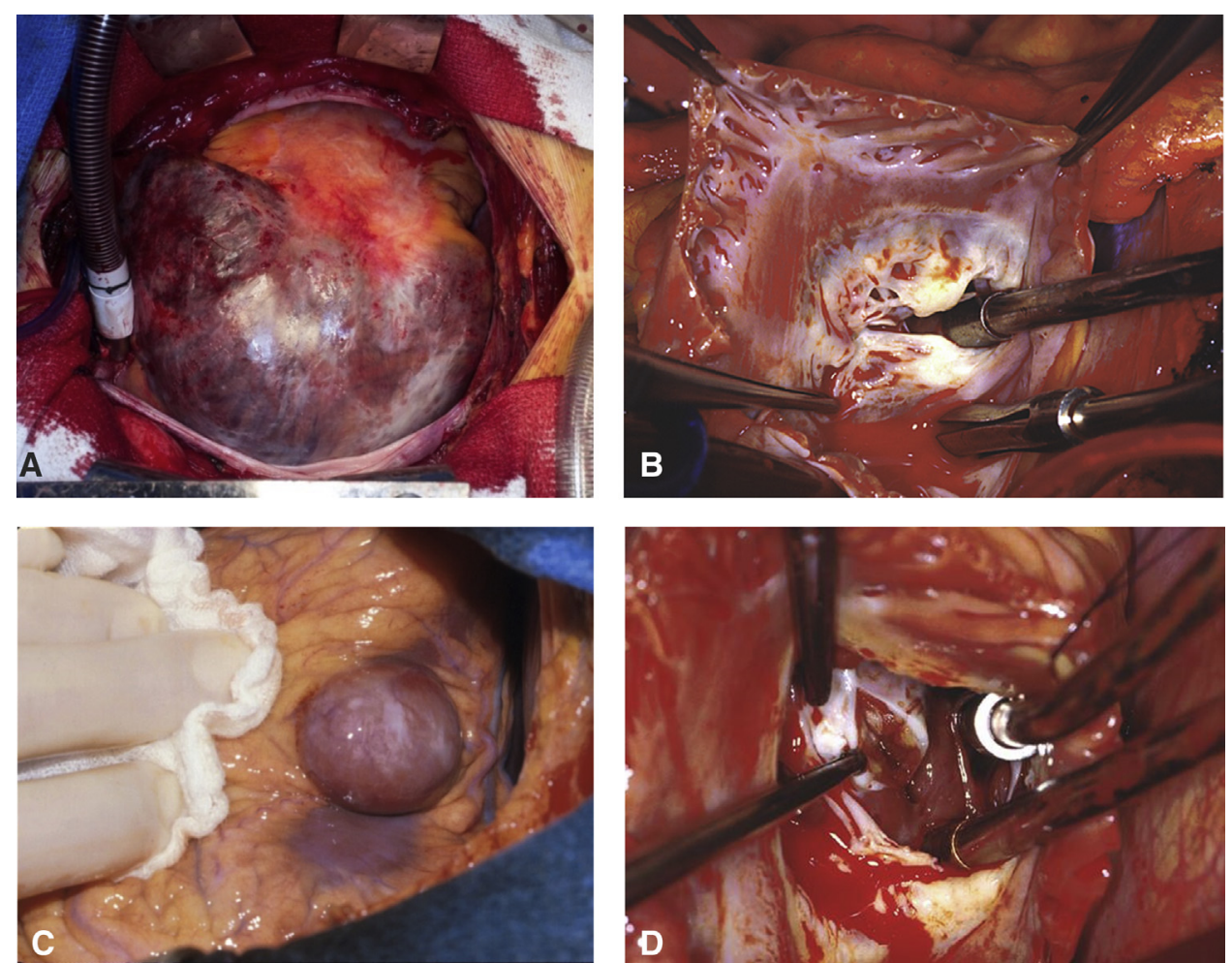

FIGURE 1. Intraoperative photographs of carcinoid heart disease. A, Enlargement of the right atrium. B, Carcinoid fibrosis of the tricuspid valve. C and D, Carcinoid metastases.

was estimated in a competing risk analysis in which death before reoperation was treated as a competing event. Prespecified preoperative variables were assessed as potential predictors of long-term mortality with multivariable Cox proportional hazards regression. Logistic regression analysis was used to analyze the association of the same factors with early mortality, although the number of 30-day deaths was too small to support a multivariable analysis. In all models, continuous predictors were expanded into multiple terms using restricted cubic splines to allow for nonlinear effects. All statistical analyses were carried out using SAS software (Version 9.4; SAS Institute Inc, Cary, NC).

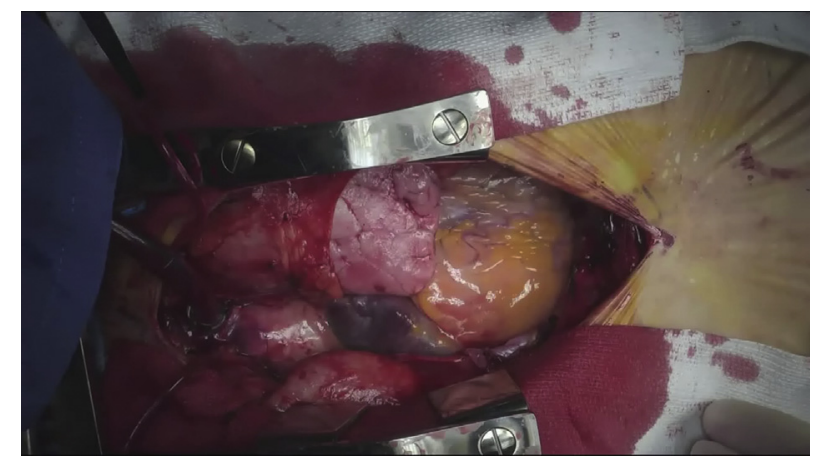

VIDEO 1. Intraoperative video of a patient with carcinoid heart disease who underwent tricuspid and pulmonary valve replacement. Video available at: https://www.jtcvs.org/article/S0022-5223(18)32526-1/fulltext.

\section{RESULTS}

\section{Baseline Characteristics and Preoperative Echocardiography}

The baseline characteristics of the study population are shown in Table 1. For these 240 patients, the median (interquartile range) age was 63 years (55-69), and 117 (49\%) were male. New York Heart Association (NYHA) class III or IV dyspnea was present in 157 patients $(70 \%)$. Loop diuretic therapy to control edema was used in 125 patients $(52 \%)$. Somatostatin analog therapy was used in 221 patients $(92 \%)$; 108 patients $(45 \%)$ received short-acting somatostatins, and from 1999 onward, when long-acting somatostatins became available, $130(72 \%)$ of 180 patients had long-acting somatostatin therapy. Markers of renal and hepatic function were normal in most patients.

Preoperative left ventricular ejection fraction was $61 \%$ (56-66). Tricuspid valve regurgitation was present in almost all patients, and 231 patients $(97 \%)$ had severe valve regurgitation on preoperative echocardiography. Severe pulmonary valve regurgitation was seen in 157 patients $(66 \%)$. Left-sided valves were less commonly affected, and severe regurgitation of the mitral or aortic valve was present in 15 patients $(6 \%)$ and 17 patients $(7 \%)$, respectively. 
TABLE 1. Baseline characteristics

\begin{tabular}{|c|c|c|}
\hline Variable & Median or $\mathbf{n}$ & IQR or percentage \\
\hline Age (y) & 63 & $(55-69)$ \\
\hline Male & 117 & $49 \%$ \\
\hline BMI $\left(\mathrm{kg} / \mathrm{m}^{2}\right)$ & 24 & $(22-27)$ \\
\hline $\operatorname{BSA}\left(\mathrm{m}^{2}\right)$ & 1.8 & $(1.7-2.0)$ \\
\hline Smoker & 90 & $38 \%$ \\
\hline Diabetes & 24 & $10 \%$ \\
\hline \multicolumn{3}{|l|}{ NYHA class } \\
\hline I & 7 & $3 \%$ \\
\hline II & 59 & $26 \%$ \\
\hline III & 122 & $55 \%$ \\
\hline IV & 35 & $16 \%$ \\
\hline Chemotherapy & 61 & $25 \%$ \\
\hline Loop diuretics & 125 & $52 \%$ \\
\hline Dose of loop diuretics (mg) & 40 & $(20-60)$ \\
\hline Somatostatin therapy & 221 & $92 \%$ \\
\hline Short-acting somatostatins & 108 & $45 \%$ \\
\hline Long-acting somatostatins & $130 / 180$ & $72 \%$ \\
\hline Creatinine $(\mathrm{mg} / \mathrm{dL})$ & 1.2 & $(1.0-1.4)$ \\
\hline AST (IU/L) & 30 & $(23-38)$ \\
\hline ALP (IU/L) & 209 & $(134-355)$ \\
\hline Total bilirubin (mg/dL) & 1.0 & $(0.7-1.5)$ \\
\hline INR & 1.2 & $(1.1-1.3)$ \\
\hline Year of surgery & 2005 & (1999-2011) \\
\hline
\end{tabular}

\section{Operative Details and Postoperative Complications}

As shown in Table 2, tricuspid valve replacement was performed in 237 patients $(99 \%)$ and bioprosthetic valves were used in 201 patients $(85 \%)$. Pulmonary valve operation was performed in 202 patients $(84 \%)$ ). Operation on left-sided valves was performed in 38 patients $(16 \%)$, and in 30 of these patients $(79 \%)$, the mitral or aortic valve dysfunction was due to carcinoid plaque. In these 38 patients with left-sided valve surgery, the atrial septum was intact in $25(66 \%)$. Median crossclamp time was 11 (7-34) minutes.

Among the 26 patients $(11 \%)$ who underwent concomitant mitral valve operations, prosthetic replacement was performed in 17 patients $(65 \%)$ who had carcinoid involvement of leaflet tissue. Mitral regurgitation was thought to be due to degenerative etiologies in 9 patients $(35 \%)$ who had repair. Likewise, 25 patients $(10 \%)$ required aortic valve intervention, of whom 19 $(76 \%)$ had valve replacements. Most patients $(\mathrm{n}=175$; $73 \%$ ) required double valve surgery, but triple and quadruple valve surgery were performed as necessary in 24 patients $(10 \%)$ and 9 patients $(4 \%)$, respectively. At the time of surgery, an atrial septal defect or patent foramen
TABLE 2. Operative details and postoperative complications

\begin{tabular}{lr}
\hline \multicolumn{1}{c}{ Variable } & $\mathbf{n}(\%)$ \\
\hline Tricuspid valve replacement & $237(99)$ \\
Mechanical valve & $36(15)$ \\
Tissue valve & $201(85)$ \\
Pulmonary valve operation & $202(84)$ \\
$\quad$ Excision & $59(29)$ \\
Valve replacement & $143(71)$ \\
Mitral valve operation & $26(11)$ \\
Repair & $9(35)$ \\
Replacement & $17(65)$ \\
Aortic valve operation & $25(10)$ \\
Repair & $6(24)$ \\
Replacement & $19(76)$ \\
\hline Left-sided operation (mitral or aortic valve) & $38(16)$ \\
No. of valves operated on & \\
Single & $32(13)$ \\
Double & $175(73)$ \\
Triple & $24(10)$ \\
Quadruple & $9(4)$ \\
ASD/PFO closure & $57(24)$ \\
Tumor excision & $6(3)$ \\
Reoperation & $27(11)$ \\
Reoperation due to bleeding & $18(8)$ \\
Postoperative permanent pacemaker implantation & $14(6)$ \\
Early (30-d) mortality & $22(9)$ \\
\hline
\end{tabular}

$A S D$, Atrial septal defect; $P F O$, patent foramen ovale.

ovale was closed in 57 patients (24\%). Cardiac metastases were excised in 6 patients ( $3 \%$ ) (Figure 1, $C$ and $D$ ).

\section{Early Mortality and Morbidity}

Early mortality, defined as death within 30 days of operation, was $9 \%$ (22 patients) over the course of the study. Early mortality decreased as time progressed and as operative experience increased (Figure 2). For operations

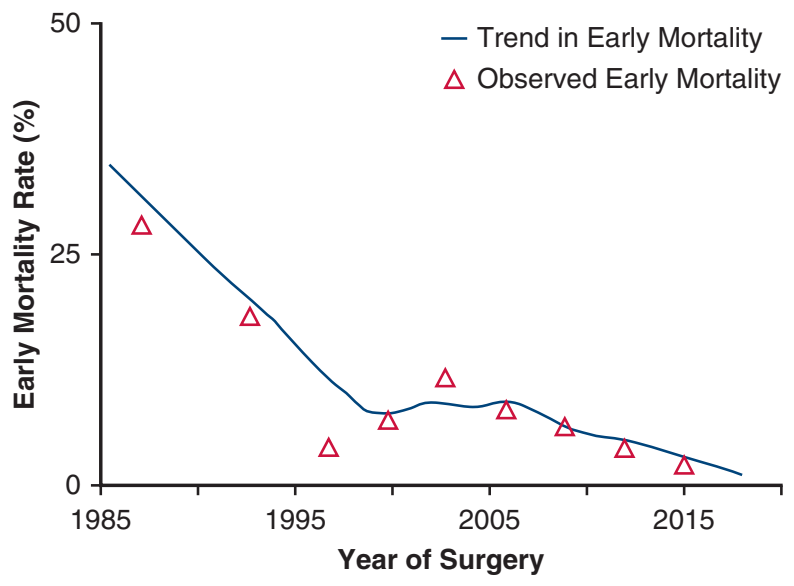

FIGURE 2. Trend in early operative mortality over study period. 
performed in our earlier experience (1985 to 1994), early mortality was $29 \%(9 / 22)$. However, the rate decreased to $7 \%(6 / 81)$ over the next 10 years (1995 to 2004) and to $5 \%$ (7/128) from 2005 onward. A more recent year of surgery correlated with older patient age (Spearman's correlation $\left.\mathrm{r}_{\mathrm{s}}=0.20, P=.002\right)$ and with lower baseline levels of total bilirubin $\left(\mathrm{r}_{\mathrm{s}}=-0.19, P=.004\right)$ and creatinine $\left(\mathrm{r}_{\mathrm{s}}=-0.17, P=.01\right)$.

On univariate analysis (Table E1), older age and higher NYHA class were associated with early mortality (odds ratio [OR], 2.31, 95\% confidence interval [CI], 1.30-4.11, $P=.008$ and OR, 2.67, 95\% CI, 1.31-5.45, $P=.007$, respectively). Use of long-acting somatostatins appeared to have some protective effects on early mortality, although this result was not statistically significant (OR, $0.45 ; 95 \%$ CI, $0.18-1.12 ; P=.085)$. The number of valves involved and presence of left-sided valve disease did not influence early mortality.

Eighteen patients $(8 \%)$ had to be taken back to the operating room because of postoperative bleeding. Fourteen patients $(6 \%)$ required permanent pacemaker insertion for complete heart block $(\mathrm{n}=12)$ or sustained sinus bradycardia $(\mathrm{n}=2)$.

\section{Late Survival and Functional Outcomes}

Figure 3 shows survival over time for the entire study population, with survival estimates at 1,3 , and 5 years of $69 \%, 48 \%$, and $34 \%$, respectively. Survival was significantly better in patients with lower preoperative NYHA class $(P<.001)$. On univariate analysis, older age, higher NYHA class, and a nonlinear effect of creatinine were associated with increased overall mortality. In a multivariable model, these factors remained independently predictive of mortality (Table 3). Use of short- or long-acting somatostatins was not associated with overall mortality. Among the late deaths in which cause was known, $80 \%$ died of noncardiac conditions, primarily tumor progression.

Early functional outcomes were assessed at a median follow-up of $0.5(0.3,0.9)$ years after surgery in 107 patients. Subanalysis of these patients showed that preoperative NYHA class III or IV symptoms were present in $64 \%$. Postoperatively, only $15 \%$ had NYHA class III limitation with no patients reporting NYHA class IV dyspnea (Figure E1).

During early follow-up, hepatic operation was performed in 21 patients $(9 \%)$. Eighteen patients had resection of hepatic metastases, and 3 patients had liver transplant.

\section{Cardiac Reintervention}

Cardiac reintervention was necessary in 20 patients $(8 \%)$ (Table E2). Figure 4 shows the cumulative incidence of cardiac valve reintervention in the presence of the competing risk of death. Reasons for reintervention were
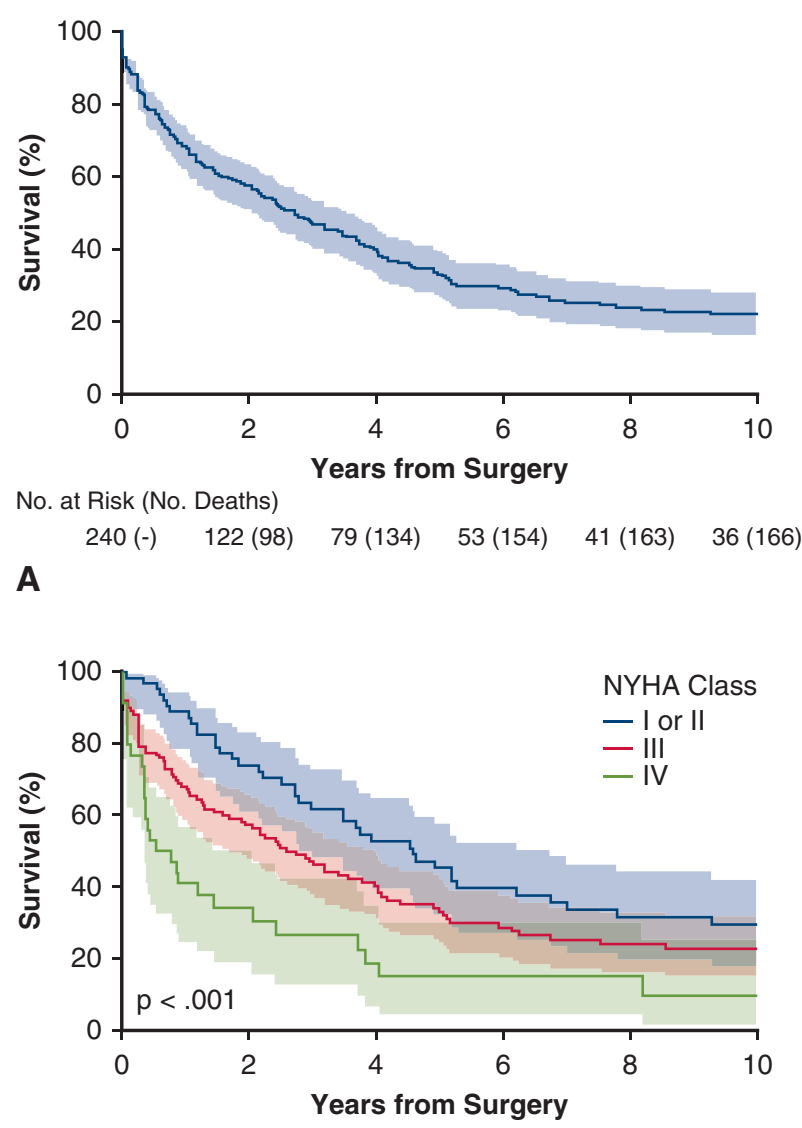

No. at Risk (No. Deaths)

$\begin{array}{cccccc}66(-) & 43(16) & 29(28) & 21(35) & 16(39) & 13(40) \\ 122(-) & 64(50) & 41(68) & 26(79) & 20(83) & 19(84) \\ -35(-) & 9(22) & 5(26) & 3(27) & 3(27) & 2(28)\end{array}$

B

FIGURE 3. A, Overall survival curve. B, Survival stratified by preoperative NYHA class. NYHA, New York Heart Association.

native or prosthetic valve dysfunction in 16 patients and pericardiectomy for constrictive pericarditis in 4 patients. Of the 16 late valve interventions, 3 were percutaneous procedures, 1 was balloon dilatation, 1 was insertion of a Melody valve (Medtronic, Minneapolis, Minn) in the pulmonary bioprosthesis, and 1 was insertion of Melody valves in dysfunctional tricuspid and pulmonary valves. Among the patients who underwent late valve operations, 2 developed carcinoid involvement of native mitral or aortic valves. Late prosthetic valve dysfunction was due to carcinoid involvement of the bioprosthesis in 3 patients. All patients with valve thrombosis had tissue bioprostheses implanted at the time of initial surgery.

\section{DISCUSSION}

This study updates and expands our surgical experience with carcinoid heart disease over a 33 -year period. ${ }^{8}$ Early mortality declined in the 240 patients who underwent surgical valve replacement during this time frame, and 
TABLE 3. Predictors of overall mortality on univariate and multivariable analysis

\begin{tabular}{|c|c|c|c|c|c|}
\hline \multirow[b]{2}{*}{ Variable } & \multirow[b]{2}{*}{ Comparison $\dashv$} & \multicolumn{2}{|c|}{ Univariate analysis } & \multicolumn{2}{|c|}{ Multivariable analysis } \\
\hline & & HR $(95 \%$ CI $)$ & $P$ value & Adjusted HR $(95 \%$ CI $) \S$ & $P$ value \\
\hline Age* & $69: 55$ & $1.37(1.10-1.69)$ & .002 & $1.55(1.22-1.97)$ & $<.001$ \\
\hline Sex & Male:Female & $1.22(0.92-1.63)$ & .171 & $1.12(0.77-1.64)$ & .548 \\
\hline $\mathrm{BMI}^{*}$ & $26.5: 21.7$ & $0.87(0.72-1.05)$ & .305 & $0.90(0.71-1.15)$ & .556 \\
\hline Short-acting somatostatin & Yes:No & $1.04(0.78-1.40)$ & .774 & $1.57(1.00-2.49)$ & .052 \\
\hline Long-acting somatostatin & Yes:No & $1.17(0.87-1.58)$ & .305 & $1.57(0.97-2.56)$ & .069 \\
\hline Loop diuretics & Yes:No & $1.22(0.91-1.63)$ & .177 & $1.13(0.80-1.57)$ & .489 \\
\hline No. of valves operated on $\dagger$ & $4: 1$ & $1.60(0.77-3.33)$ & .210 & $1.06(0.34-3.38)$ & .916 \\
\hline Left-sided operation & Yes:No & $1.29(0.88-1.90)$ & .195 & $1.52(0.81-2.85)$ & .190 \\
\hline NYHA class $\dagger$ & III:II & $1.48(1.18-1.85)$ & .001 & $1.53(1.15-2.03)$ & .004 \\
\hline $\mathrm{AST}^{*}$ & $37.5: 23$ & $0.98(0.75-1.28)$ & .185 & $1.15(0.84-1.55)$ & .196 \\
\hline Total bilirubin* & $1.5: 0.7$ & $1.09(0.82-1.45)$ & .833 & $1.05(0.76-1.46)$ & .892 \\
\hline Creatinine* & $1.4: 1.0$ & $0.98(0.79-1.22)$ & $<.001$ & $0.81(0.63-1.06)$ & .013 \\
\hline
\end{tabular}

HR, Hazard ratio; $C I$, confidence interval; BMI, body mass index; NYHA, New York Heart Association; AST, aspartate transaminase. *Continuous variables were expanded into multiple terms using restricted cubic splines (using 3 knots) to allow for nonlinear effects and assessed for general association based on a 2 d.f. test. $\dagger$ Because of data discreteness, a linear relationship was assumed for numeric variable ( 1 d.f. test). $‡$ Effects of predictor variables were estimated with unadjusted and adjusted hazard ratios (and $95 \%$ confidence limits) from univariable and multivariable models, respectively. Unless noted otherwise, continuous variables are reported as interquartile range hazard ratios (comparing the 75 th percentile with the 25th percentile of the predictor). Because these variables are modeled nonlinearly, confidence limits of the hazard ratio are not necessarily consistent with general tests of association. That is, inclusion of 1.0 in the interval does not imply nonsignificance, and conversely, it is possible to have intervals excluding 1.0 without having evidence of an overall association. $\S$ A multivariable Cox regression model was fitted for all-cause mortality on $\mathrm{n}=214$ who had complete data for predictor variables shown in the table.

risk of perioperative death was associated with older age and more advanced heart failure (higher NYHA class); although not significant, long-acting somatostatins may have some protective effect on early mortality. The study adds important information on durability of valve prostheses in patients with carcinoid heart disease.

In previous reports, operative mortality for valve replacement in patients with carcinoid heart disease has ranged from $18 \%$ to $63 \%$, but most of these series were small with fewer than 50 patients. ${ }^{17}$ In the present series between 1985 and 1994, early mortality was $29 \%$; this risk decreased to $7 \%$ between 1995 and 2004, and has been $5 \%$ in the 128 patients undergoing operation since 2005 (Figure 2). Recent studies have reported similar early risks, $5 \%$ to $10 \% .{ }^{18,19}$ Indeed, in current practice, multiple valve replacement for carcinoid heart disease has an operative risk similar to that for multiple valve disease of other etiologies $(8 \%-13 \%) .{ }^{20}$ It is notable that the number of valves replaced was not predictive of mortality in this surgical cohort.

Decreasing early mortality may be due to multiple factors, including refinement in patient selection and improved overall surgical care. These measures, especially improved perioperative management, are difficult to quantify and were not captured in our database.

However, increased early mortality was associated with older age and higher NYHA class at presentation (Table E1), suggesting that patients with carcinoid heart disease may benefit from earlier surgical intervention. Indeed, in our more recent experience, patients with carcinoid heart disease had less severe symptoms, and this accounts, in part, for better outcome. Some clinicians argue that operation should be performed before onset of significant functional impairment, and Bhattacharyya and colleagues ${ }^{3,21}$ reported NYHA class I or II symptoms in $55 \%$ of 22 patients with carcinoid heart disease who underwent cardiac surgery at their institution. Nevertheless, optimal timing of surgery may be difficult to determine in these complex patients whose symptoms occur in combination with gastrointestinal/hepatic impairment. For example, it is often challenging to determine to what degree right heart failure is contributing to functional decline and ascites in a patient with carcinoid syndrome and extensive hepatic metastases.

In our cohort, survival at 3 years was $48 \%$, but was significantly better in patients with NYHA class I or II symptoms preoperatively (Figure 3). Overall survival of our surgical patients compares favorably to medically managed patients with carcinoid heart disease, in whom 3 -year survival estimates of $31 \%$ have been reported. ${ }^{1}$ In most patients, late survival after valve replacement for carcinoid heart disease is limited by tumor progression. Despite limitations of overall survival in patients undergoing valve surgery for carcinoid heart disease, early functional outcomes were excellent (Figure E1). Symptoms from right-sided heart failure were greatly improved in the majority of patients, and enhanced quality of life should be considered in these patients with limited life expectancy.

An important consideration for patients undergoing valve replacement is the choice of valve prosthesis. At the Mayo 


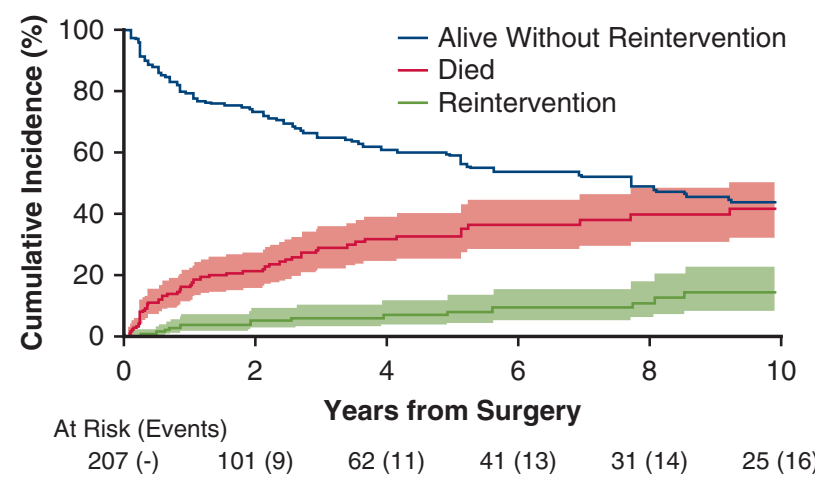

FIGURE 4. Cumulative risk of cardiac valve reintervention.

Clinic, we have generally preferred tissue valves for patients with carcinoid heart disease; bioprostheses were implanted in more than $80 \%$ of patients. Tissue valves are appropriate for most patients with carcinoid heart disease who have limited life expectancy. Exceptions to this practice include patients who require anticoagulation with warfarin for other reasons or patients with ovarian carcinoid tumors who have a favorable outlook after valve surgery and oophorectomy. ${ }^{22}$ However, as seen in the present review, tissue bioprostheses were not free of risk from thrombosis; 3 patients required surgical reintervention because of thrombosis of a bioprosthetic valve. Thus, anticoagulation is advised for patients receiving tissue bioprostheses, and we suggest using warfarin for 3 to 6 months for patients in sinus rhythm and indefinitely for those with atrial fibrillation., ${ }^{4,23}$

Recurrent carcinoid fibrosis of bioprostheses is another concern for patients undergoing valve replacement with tissue valves. In our series, this was documented by pathologic examination of valves from 3 patients (Table E2). Carcinoid recurrence seems to be a rare complication, but has been reported by van Rijswijk and colleagues. ${ }^{25}$ In the present series, carcinoid involvement of bioprostheses occurred between 3 and 8 years after initial surgery, but cause(s) of recurrence could not be ascertained from our data. Two of these 3 patients were treated with somatostatins preoperatively and remained on this medication after surgery; 24-hour urinary 5-hydroxyindoleacetic acid levels were elevated before reoperation in 1 of these patients. The other patient had no systemic symptoms from his metastatic carcinoid tumor and did not receive somatostatin therapy preoperatively or postoperatively. It is important to note that valve thrombosis and carcinoid recurrence occurred only in patients who received tissue bioprostheses, and thus mechanical heart valves may be appropriate for some patients, such as young patients in whom further surgical treatment of primary or metastatic tumor is not planned. ${ }^{9}$

In the present series, left-sided heart valves were replaced or repaired in $16 \%$ of patients. However, presence of left-sided disease did not appear to be associated with intracardiac shunts because $66 \%$ of these patients had an intact atrial septum. This result is consistent with those reported by Connolly and colleagues, ${ }^{6}$ who observed left-sided heart disease without shunts in $55 \%$ of their study population. Furthermore, presence of left-sided heart disease was not associated with early or overall mortality in our cohort. In our experience, surgery in patients with associated aortic or mitral valve regurgitation is safe and should be performed if clinically indicated.

\section{Study Limitations}

This is a retrospective study from a single center and may be influenced by referral bias. These surgical results also reflect the importance of an experienced team specializing in carcinoid heart disease and may not be replicable at other institutions.

\section{CONCLUSIONS}

Operation on patients with carcinoid valvular disease leads to excellent improvement in symptoms during early follow-up and has acceptable short-term mortality and complication rates. Early mortality has improved in recent experience, but overall survival is limited by tumor progression. Bioprostheses are appropriate for most patients because structural valve deterioration due to carcinoid involvement is rare.

\section{Conflict of Interest Statement}

Authors have nothing to disclose with regard to commercial support.

\section{References}

1. Pellikka PA, Tajik AJ, Khandheria BK, Seward JB, Callahan JA, Pitot HC, et al Carcinoid heart disease. Clinical and echocardiographic spectrum in 74 patients. Circulation. 1993;87:1188-96.

2. Lundin L, Norheim I, Landelius J, Oberg K, Theodorsson-Norheim E. Carcinoid heart disease: relationship of circulating vasoactive substances to ultrasounddetectable cardiac abnormalities. Circulation. 1988;77:264-9.

3. Bhattacharyya S, Toumpanakis C, Caplin ME, Davar J. Analysis of 150 patients with carcinoid syndrome seen in a single year at one institution in the first decade of the twenty-first century. Am J Cardiol. 2008;101:378-81.

4. Davar J, Connolly HM, Caplin ME, Pavel M, Zacks J, Bhattacharyya S, et al. Diagnosing and managing carcinoid heart disease in patients with neuroendocrine tumors: an expert statement. J Am Coll Cardiol. 2017;69:1288-304.

5. Fox DJ, Khattar RS. Carcinoid heart disease: presentation, diagnosis, and management. Heart. 2004;90:1224-8.

6. Connolly HM, Schaff HV, Mullany CJ, Rubin J, Abel MD, Pellikka PA. Surgical management of left-sided carcinoid heart disease. Circulation. 2001;104(12 Suppl 1):I36-40.

7. Arghami A, Connolly HM, Abel MD, Schaff HV. Quadruple valve replacement in patients with carcinoid heart disease. J Thorac Cardiovasc Surg. 2010;140: 1432-4.

8. Connolly HM, Schaff HV, Abel MD, Rubin J, Askew JW, Li Z, et al. Early and late outcomes of surgical treatment in carcinoid heart disease. J Am Coll Cardiol. 2015;66:2189-96.

9. Lillegard JB, Fisher JE, Mckenzie TJ, Que FG, Farnell MB, Kendrick ML, et al. Hepatic resection for the carcinoid syndrome in patients with severe carcinoid heart disease: does valve replacement permit safe hepatic resection? J Am Coll Surg. 2011;213:130-8. 
10. Weingarten TN, Abel MD, Connolly HM, Schroeder DR, Schaff HV. Intraoperative management of patients with carcinoid heart disease having valvular surgery: a review of one hundred consecutive cases. Anesth Analg. 2007;105:1192-9.

11. Møller JE, Pellikka PA, Bernheim AM, Schaff HV, Rubin J, Connolly HM. Prognosis of carcinoid heart disease: analysis of 200 cases over two decades. Circulation. 2005;112:3320-7.

12. Strosberg J, Weber J, Feldman M, Goldman J, Almhanna K, Kvols L. Above-label doses of octreotide-LAR in patients with metastatic small intestinal carcinoid tumors. Gastrointest Cancer Res. 2013;6:81-5.

13. Ramage JK, Ahmed A, Ardill J, Bax N, Breen DJ, Caplin ME, et al. Guidelines for the management of gastroenteropancreatic neuroendocrine (including carcinoid) tumours (NETs). Gut. 2012;61:6-32.

14. Killu AM, Newman DB, Miranda WR, Maleszewski JJ, Pellikka P, Schaff HV, et al. Carcinoid heart disease without severe tricuspid valve involvement. Cardiology. 2016;133:217-22.

15. Connolly HM, Schaff HV, Mullany CJ, Abel MD, Pellikka PA. Carcinoid heart disease: impact of pulmonary valve replacement in right ventricular function and remodeling. Circulation. 2002;106(12 Suppl 1):I51-6.

16. Whitlock RP, Sun JC, Fremes SE, Rubens FD, Teoh KH. Antithrombotic and thrombolytic therapy for valvular disease: antithrombotic therapy and prevention of thrombosis, 9th ed: American College of Chest physicians evidence-based clinical practice guidelines. Chest. 2012;141(2 Suppl):e576S-600S.

17. Castillo JG, Milla F, Adams DH. Surgical management of carcinoid heart valve disease. Semin Thorac Cardiovasc Surg. 2012;24:254-60.

18. Kuntze T, Owais T, Secknus M-A, Kaemmerer D, Baum R, Girdauskas E. Results of contemporary valve surgery in patients with carcinoid heart disease. $J$ Heart Valve Dis. 2016;25:356-63.

19. Mokhles P, van Herwerden LA, de Jong PL, de Herder WW, Siregar S, Constantinescu AA, et al. Carcinoid heart disease: outcomes after surgical valve replacement. Eur J Cardiothorac Surg. 2012;41:1278-83.

20. Rankin JS, He X, O'Brien SM, Jacobs JP, Welke KF, Filardo G, et al. The Society of Thoracic Surgeons risk model for operative mortality after multiple valve surgery. Ann Thorac Surg. 2013;95:1484-90.

21. Bhattacharyya S, Raja SG, Toumpanakis C, Caplin ME, Dreyfus GD, Davar J. Outcomes, risks and complications of cardiac surgery for carcinoid heart disease. Eur J Cardiothorac Surg. 2011;40:168-72.

22. Chaowalit N, Connolly HM, Schaff HV, Webb MJ, Pellikka PA. Carcinoid heart disease associated with primary ovarian carcinoid tumor. Am J Cardiol. 2004;93: 1314-5.

23. Egbe AC, Connolly HM, Pellikka PA, Schaff HV, Hanna R, Maleszewski JJ, et al. Outcomes of warfarin therapy for bioprosthetic valve thrombosis of surgically implanted valves: a prospective study. JACC Cardiovasc Interv. 2017;10:379-87.

24. Egbe A, Pislaru SV, Ali MA, Khan AR, Boler AN, Schaff HV, et al. Early prosthetic valve dysfunction due to bioprosthetic valve thrombosis: the role of echocardiography. JACC Cardiovasc Imaging. 2018;11:951-8.

25. van Rijswijk JW, Vink A, van Herwerden LA, Kluin J. Recurrent carcinoid involvement of a tricuspid bioprosthesis. Eur J Cardiothorac Surg. 2017;51:1015.

Key Words: carcinoid heart disease, tricuspid valve, surgery

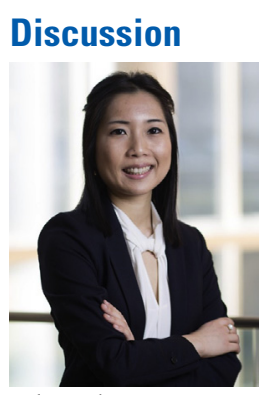

Dr Anita Nguyen (Rochester, Minn). Good morning. My name is Anita Nguyen, and I'm a research fellow at Mayo Clinic. Today I am presenting our study on improving outcomes of valve replacement for patients with carcinoid heart disease. We have no disclosures, but would like to acknowledge the very generous support of the Paul and Ruby Tsai family.
Carcinoid heart disease occurs in patients with carcinoid tumors, which are neuroendocrine malignancies secreting high levels of serotonin. This affects $20 \%$ to $50 \%$ of patients with carcinoid syndrome and can cause symptoms of rightsided heart failure and fibrosis, mainly affecting the tricuspid and pulmonary valves. In patients with right-sided heart failure symptoms, surgical valve replacement may be indicated. At the Mayo Clinic, we have operated on 240 patients with carcinoid heart disease over a 33-year period. The median age of patients was 63 years, and approximately half of our patients were male. Preoperatively, approximately $75 \%$ were in NYHA class III or IV.

Loop diuretic therapy was necessary in approximately half of our patients, and the majority of patients required somatostatin analogue therapy. Hepatic metastases are common in patients with carcinoid heart disease, but despite this, our patients had normal renal and liver function. This table shows the operative details. The majority of patients underwent tricuspid valve replacement, and $84 \%$ had tissue valves. Left-sided heart valves are less commonly affected by carcinoid heart disease, and $16 \%$ required operation on the aortic or mitral valve. Concomitant atrial septal defect or patent foramen ovale closure was necessary in $24 \%$ of patients. We excised cardiac tumors, which were a rare complication of carcinoid heart disease in 6 patients.

After surgery, early mortality, which we defined as death within 30 days of operation, occurred in $9 \%$ of patients. Before 2000 , our early operative mortality was $17 \%$, and after 2000, this decreased to $6 \%$. On univariate analysis, higher NYHA class and older age was predictive of early mortality. Higher aspartate transaminase levels, which are associated with liver dysfunction, were somewhat predictive. This graph shows the overall survival of our study population. Of note, most of the late deaths occurred as the result of tumor progression. We grouped our patients by NYHA class and noticed that patients with NYHA class 1 or 2 had significantly better survival.

We then conducted univariate and multivariable analyses and noticed that older age and higher NYHA class were independently predictive of overall mortality. These graphs show the association between log relative hazard and age and NYHA class. The association was linear for both age and NYHA, which means that the higher the age or the higher the NYHA class, the higher the risk of overall mortality. Twenty patients required cardiac reintervention, and 16 patients required valve reintervention at a mean follow-up of 6 years. Only 3 patients required valve reintervention because of recurrence of carcinoid heart disease, and pericardiectomy for constrictive pericarditis was necessary in 4 patients. This graph shows patients alive without reintervention in dark blue and the cumulative incidence of reintervention in light blue. We assessed functional outcomes at 1 year in 107 patients and noticed that preoperatively, more than $65 \%$ were in NYHA class 3 or 4 , and 
postoperatively, this number decreased to less than $15 \%$.

Patients with carcinoid heart disease who undergo valve surgery have improved early mortality, late survival is limited by tumor progression, the majority of patients experience symptomatic improvement, carcinoid involvement of bioprosthesis is rare, and earlier operation may decrease operative mortality and increase overall survival.

Questioner. Can you tell us how many patients still had tumor burden after the surgery and whether they ever received complete resection of the primary?

Dr Nguyen. The primary indication for performing the surgery was that most patients already had hepatic metastases at presentation, and we operated on the valves in view of future resection of the metastases, but it's rare for patients who are disease free to be completely disease free. This is only something that occurs with certain types of carcinoid tumors, such as ovarian cancers.

Questioner. What is your valve of choice, and if it's a bioprosthesis, is there any special novel therapy that you're doing to try to prevent carcinoid to involve a bioprosthetic valve?

Dr Nguyen. The valve of choice in this series was a bioprosthesis, and $84 \%$ of patients had a bioprosthesis. There is nothing specific that we can recommend to decrease the risk of carcinoid heart involvement in the future; however, the risk in this series was small, 3 of 240 patients.

Questioner. When you compare your historical mortality, that is pre-2000, it is $17 \%$ versus $6 \%$. What other things did you change and do you think that might reflect just better management of the right ventricle? As I reflect upon this, I would have to assume that age and NYHA class are robust risk factor predictors, but perhaps it was better management of right ventricular dysfunction perioperatively that led to the better results. Is this true?
Dr Nguyen. Yes, we tried to ascertain the causes of the decrease in early mortality, and it was difficult for us to really pinpoint what exactly was causing the decrease in early mortality. We think it's a combination of better patient selection and improvement in general management of carcinoid heart disease with newer medical therapies.

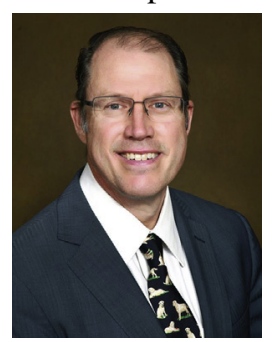

Dr Joseph Cleveland (Aurora, Colo). Are you using valve-in-valve transcatheter aortic valve replacement technology to salvage some of the recurrent disease in the right-sided heart valves? Dr Nguyen. We performed 2 percutaneous right-sided reinterventions.

Dr Cleveland. Hartzell?

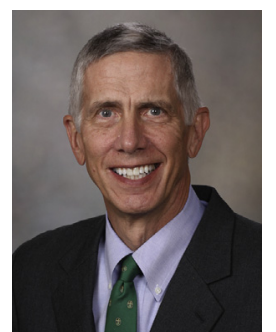

Dr Hartzell Schaff (Rochester, Minn). Just to clarify a point that Anita made about the treatment of patients afterward with bioprosthesis. We don't know for certain but would advise continued use of somatostatins that might have an influence on reducing the risk of carcinoid development on the bioprosthesis. The perioperative deaths are not related necessarily to right heart failure, and in fact, that's an uncommon cause of death. Most of the deaths are due to hepatic and renal failure, and liver function tests don't really predict who's going to have hepatic insufficiency after operation, so that's a challenge. Your last question had to do with how many of these patients were disease free. All of the patients had hepatic metastases except for 2 or 3 patients who had ovarian carcinoid tumors, who have serotonin going directly into the heart. So all of the patients had metastatic disease at the time we operated on them and afterward. 


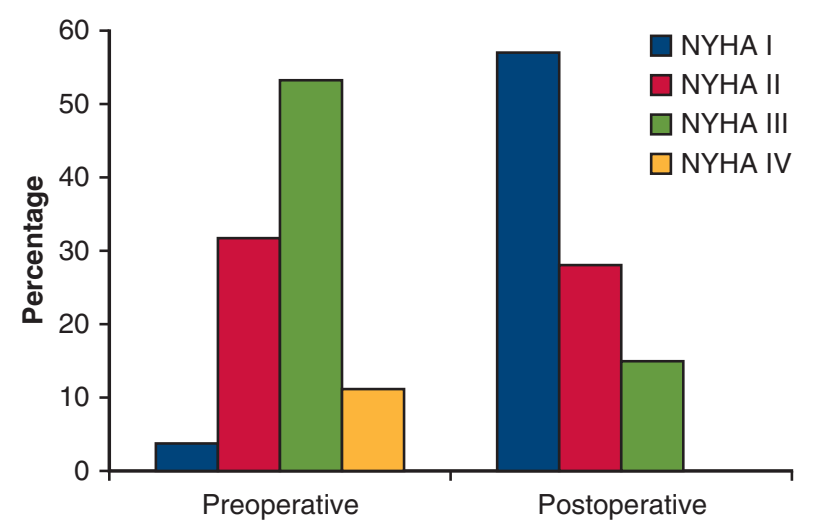

FIGURE E1. Functional outcomes of 107 patients at median follow-up of $0.5(0.3-0.9)$ years. NYHA, New York Heart Association.

TABLE E1. Predictors of early mortality on univariate analysis

\begin{tabular}{llll}
\hline \multicolumn{1}{c}{ Variable } & Comparison $\neq$ & OR (95\% CI) & P value \\
\hline Age* & $69: 25$ & $2.31(1.30-4.11)$ & .008 \\
Sex & Male:Female & $0.86(0.36-2.08)$ & .746 \\
\hline BMI* & $26.5: 21.7$ & $1.04(0.60-1.78)$ & .826 \\
Short-acting somatostatins & Yes:No & $1.87(0.77-4.56)$ & .169 \\
\hline Long-acting somatostatins & Yes:No & $0.45(0.18-1.12)$ & .085 \\
Loop diuretics & Yes:No & $1.69(0.68-4.18)$ & .259 \\
No. of valves operated on $\dagger$ & 1 -level increase & $1.01(0.50-2.05)$ & .976 \\
Left-sided operation & Yes:No & $0.83(0.23-2.94)$ & .767 \\
NYHA class $\dagger$ & $1-$ level increase & $2.67(1.31-5.45)$ & .007 \\
AST* & $38: 23$ & $1.87(1.06-3.30)$ & .067 \\
Total bilirubin* & $1.5: 0.7$ & $1.15(0.47-2.80)$ & .559 \\
Creatinine* & $1.4: 1.0$ & $1.14(0.58-2.25)$ & .906 \\
\hline
\end{tabular}

$O R$, Odds ratio; $C I$, confidence interval; $B M I$, body mass index; $N Y H A$, New York Heart Association; $A S T$, aspartate transaminase. *Continuous variables were expanded into multiple terms using restricted cubic splines (using 3 knots) to allow for nonlinear effects, and assessed for general association based on a 2 d.f. test. $\dagger$ Because of data discreteness, a linear relationship was assumed for the numeric variable (1 d.f. test). $\ddagger$ Effects are estimated as unadjusted ORs (and $95 \%$ CIs) from univariable logistic regression models. Unless noted otherwise, continuous variables are reported as IQR ORs (comparing the 75th percentile with the 25th percentile of the predictor). Because these variables are modeled nonlinearly, CIs of the ORs will not be entirely consistent with general tests of association, unlike the case with linear effects. That is, inclusion of 1.0 in the interval does not imply nonsignificance, and conversely, it is possible to have intervals excluding 1.0 without having evidence of a significant association. 
TABLE E2. Details of cardiac valve reintervention

\begin{tabular}{|c|c|c|c|c|c|}
\hline Patient & $\begin{array}{c}\text { Year of } \\
\text { initial } \\
\text { surgery }\end{array}$ & $\begin{array}{c}\text { Time to } \\
\text { reintervention } \\
(\mathbf{y})\end{array}$ & $\begin{array}{l}\text { Initial procedure on the valve } \\
\text { requiring reintervention }\end{array}$ & Reintervention procedure & Additional details \\
\hline 1 & 1992 & 0.9 & Pulmonary homograft & $\begin{array}{l}\text { Percutaneous balloon dilatation } \\
\text { of pulmonary valve }\end{array}$ & $\begin{array}{l}\text { Pulmonary artery rupture after } \\
\text { percutaneous procedure }\end{array}$ \\
\hline 2 & 1994 & 2.6 & Tricuspid bioprosthesis & Tricuspid valve replacement & $\begin{array}{l}\text { Carcinoid recurrence of tricuspid } \\
\text { bioprosthesis }\end{array}$ \\
\hline 3 & 1995 & 0.5 & $\begin{array}{l}\text { Tricuspid and pulmonary } \\
\text { bioprostheses }\end{array}$ & $\begin{array}{l}\text { Tricuspid and pulmonary } \\
\text { valve replacement }\end{array}$ & Thrombosis of both bioprostheses \\
\hline 4 & 1996 & 0.9 & $\begin{array}{l}\text { Tricuspid bioprosthesis, } \\
\text { pulmonary homograft }\end{array}$ & $\begin{array}{l}\text { Tricuspid and pulmonary } \\
\text { valve replacement }\end{array}$ & $\begin{array}{l}\text { Tricuspid valve thrombosis, } \\
\text { pulmonary homograft stenosis }\end{array}$ \\
\hline 5 & 1997 & 14.5 & $\begin{array}{l}\text { Native mitral valve, tricuspid } \\
\text { mechanical prosthesis }\end{array}$ & $\begin{array}{l}\text { Mitral and tricuspid } \\
\text { valve replacement }\end{array}$ & $\begin{array}{l}\text { Mitral valve stenosis (late carcinoid } \\
\text { involvement) }\end{array}$ \\
\hline 6 & 1997 & 12.7 & Pulmonary valvectomy & Pulmonary valve replacement & $\begin{array}{l}\text { Severe pulmonary valve regurgitation } \\
\text { (s/p valvectomy) }\end{array}$ \\
\hline 7 & 1997 & 5.0 & $\begin{array}{l}\text { Native aortic valve, } \\
\text { pulmonary valvectomy }\end{array}$ & $\begin{array}{l}\text { Aortic and pulmonary } \\
\text { valve replacement }\end{array}$ & $\begin{array}{l}\text { Aortic valve regurgitation (late } \\
\text { carcinoid involvement), severe } \\
\text { pulmonary valve regurgitation } \\
\text { (s/p valvectomy) }\end{array}$ \\
\hline 8 & 1997 & 13.6 & $\begin{array}{l}\text { Tricuspid bioprosthesis, } \\
\text { pulmonary valvectomy }\end{array}$ & $\begin{array}{l}\text { Tricuspid and pulmonary } \\
\text { valve replacement }\end{array}$ & $\begin{array}{l}\text { Thrombosis of tricuspid } \\
\text { bioprosthesis, severe pulmonary } \\
\text { valve regurgitation (s/p } \\
\text { valvectomy) }\end{array}$ \\
\hline 9 & 2001 & 8.6 & $\begin{array}{l}\text { Tricuspid and pulmonary } \\
\text { bioprostheses }\end{array}$ & $\begin{array}{l}\text { Tricuspid and pulmonary } \\
\text { valve replacement }\end{array}$ & $\begin{array}{l}\text { Carcinoid recurrence of both } \\
\text { bioprostheses }\end{array}$ \\
\hline 10 & 2001 & 7.8 & $\begin{array}{l}\text { Tricuspid and pulmonary } \\
\text { bioprostheses }\end{array}$ & $\begin{array}{l}\text { Tricuspid and pulmonary } \\
\text { valve replacement }\end{array}$ & $\begin{array}{l}\text { Carcinoid recurrence of both } \\
\text { bioprostheses }\end{array}$ \\
\hline 11 & 2002 & 10.2 & $\begin{array}{l}\text { Tricuspid and pulmonary } \\
\text { bioprostheses }\end{array}$ & $\begin{array}{l}\text { Tricuspid and pulmonary } \\
\text { valve replacement }\end{array}$ & $\begin{array}{l}\text { Unknown etiology, reintervention at } \\
\text { outside hospital }\end{array}$ \\
\hline 12 & 2004 & 8.2 & Pulmonary bioprosthesis & $\begin{array}{l}\text { Percutaneous pulmonary } \\
\text { valve replacement }\end{array}$ & Severe pulmonary valve regurgitation \\
\hline 13 & 2004 & 4.0 & Tricuspid bioprosthesis & Tricuspid valve replacement & Thrombosis of tricuspid bioprosthesis \\
\hline 14 & 2007 & 5.7 & $\begin{array}{l}\text { Tricuspid and pulmonary } \\
\text { bioprostheses }\end{array}$ & $\begin{array}{l}\text { Percutaneous tricuspid and } \\
\text { pulmonary valve replacement }\end{array}$ & $\begin{array}{l}\text { Severe tricuspid and pulmonary valve } \\
\text { regurgitation }\end{array}$ \\
\hline 15 & 2009 & 1.9 & Tricuspid bioprosthesis & Tricuspid valve replacement & $\begin{array}{l}\text { Pannus overgrowth of tricuspid } \\
\text { bioprosthesis cusps }\end{array}$ \\
\hline 16 & 2015 & 2.0 & $\begin{array}{l}\text { Tricuspid and pulmonary } \\
\text { bioprostheses }\end{array}$ & $\begin{array}{l}\text { Tricuspid and pulmonary } \\
\text { valve replacement }\end{array}$ & $\begin{array}{l}\text { Structural valve deterioration due to } \\
\text { infective endocarditis }\end{array}$ \\
\hline
\end{tabular}

